\title{
RADIO-FREQUENCY RESISTANCE AND INDUCTANCE OF COILS USED IN BROADCAST RECEPTION
}

\author{
By August Hund and H. B. De Groot
}

\begin{abstract}
This paper gives experimental data on the radio-frequency resistance and inductance of certain "low loss" coils within the range of broadcast frequencies. The coils are of different shapes and wound with different kinds of wire. The results are plotted in graphs so that the reader can use them for selecting a coil for a desired purpose. For the data to apply it is necessary that the coil be constructed in accordance with the information given in a table. The dimensions are such that the coils are suitable for modern broadcast reception. A discussion of the important characteristics of coils is given. Of the coils measured the loose basket weave coil and the single-layer coil have the lowest radiofrequency resistance. Where a binder is required for holding the turns in position, collodion introduces the least amount of resistance. For the entire range of broadcast frequencies (500 to 1,500 kc) No. 32-38 litz has somewhat smaller resistance than No. 24 AWG d. c. c. wire; however, for most work No. 24 wire is suitable.
\end{abstract}

\section{CONTENTS}

1. Introduction . . Page

II. Procedure

III. Description of test samples

IV. Results_............. 658

1. Effect of the kind of wire on the resistance of a coil_____._ 660

2. Effect of broken strands in litz wire

3. Effect of binder on the efficiency of coils

V. Summary

\section{INTRODUCTION}

The purpose of this paper is to present data on the radio-frequency resistance and inductance of coils within the range of frequencies used in radiotelephone broadcasting. The coils are of different shapes and wound with different kinds of wire. The method of measurement used is indicated in Figure 1; it was described in detail by one of the authors ${ }^{1}$ in 1924 . The effective resistance $R$ was found by direct comparison with a standard variable resistance $R_{\mathrm{s}}$

1 August Hund, "Measurements at radio frequency," Elect. World, 84, pp. 998-1000; Nov. 8, 1924. 
after the test coil and the condenser $C$ had been tuned to resonance. The apparent inductance was calculated from the formula

$$
L=\frac{25350}{f^{2} C}
$$

where the inductance $L$ is in microhenries, frequency $f$ in kilocycles per second, and the measured resonance capacity $C$ of the series condenser is in microfarads.

\section{PROCEDURE}

The method employed was to compare at radio-frequency coils of several types commonly used in receiving sets. The coils had been adjusted to the same self-inductance at a frequency of $1 \mathrm{kc}$ per

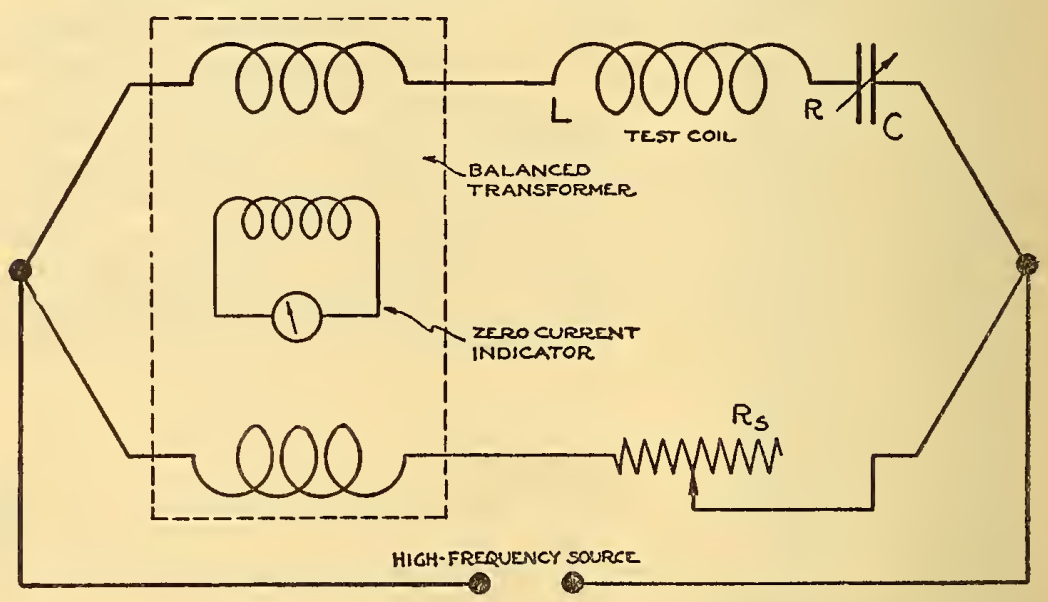

Fig. 1.-Arrangement for the determination of radio-frequency resistance and inductance

second. This represents the minimum value of the apparent inductance, larger values being obtained at the broadcast frequencies. The direct-current resistance was different for the various coils, since some shapes required more wire than others for the same inductance at $1 \mathrm{kc}$.

The quality of coils can be considered in terms of a number of different properties, ${ }^{2}$ each of which is of importance in the use of

\footnotetext{
a It may help the reader to recall that the function of the coil is essentially to introduce inductance in the circuit, a given amount of inductance being introduced with the minimum possible length of wire and of resistance. On account of the capacity action of a coil the apparent inductance is usually much larger at broadcast frequencies, since the decrease due to skin effect action is small in comparison. The capacity action of a coil tends to transfer more or less energy across the turns than along them, thus turning the coil with increasing frequency gradually into a condenser with a resistance which is due to the insulation between the turns.
} 

Technologic Papers of the Bureau of Standards, Vol. 19

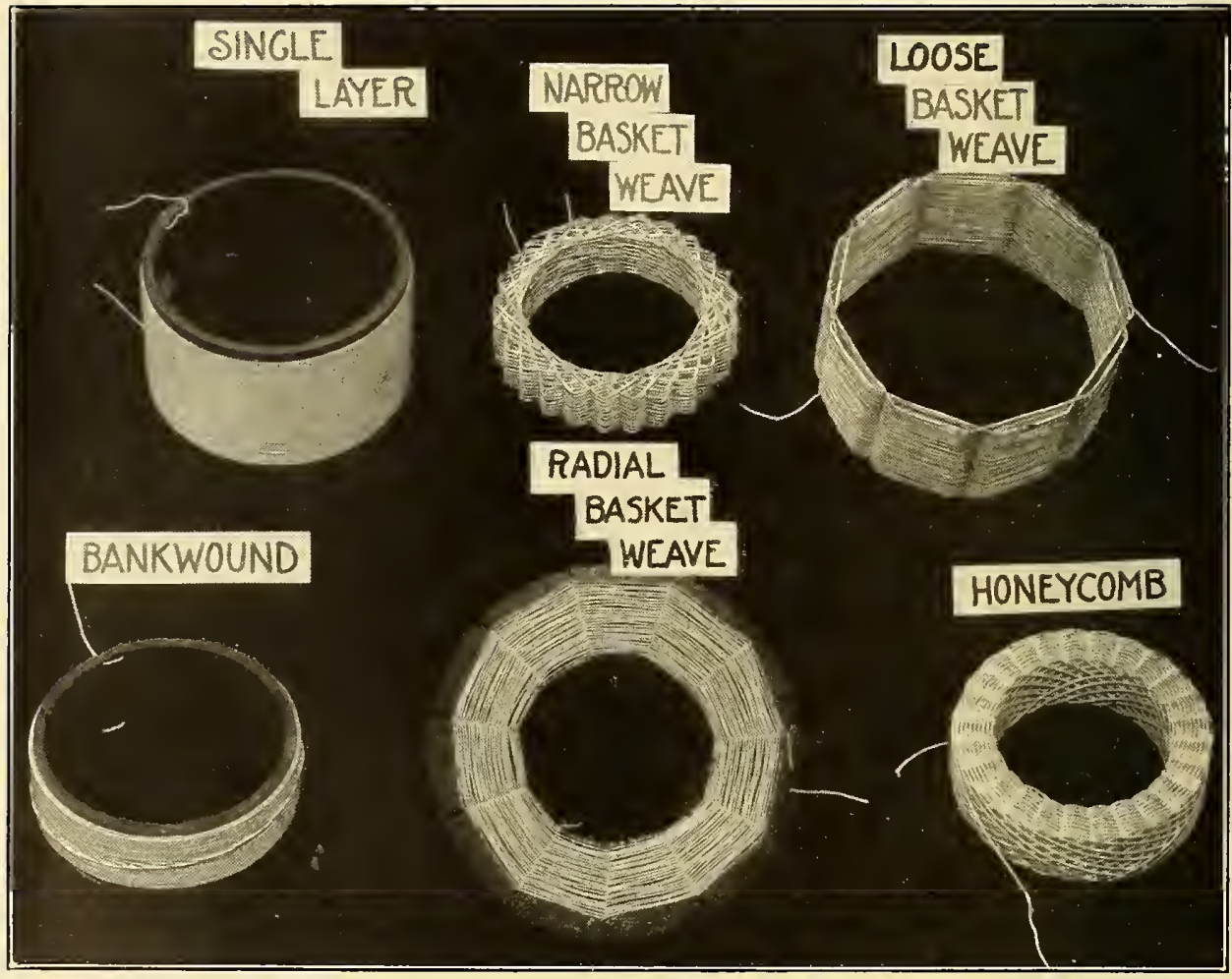

FIG. 2.--Low-loss coils used for measurement 
the coil. For use in the tuned circuits of a receiving set the important characteristics are:

(a) The radio-frequency resistance. A low value of resistance at the actual frequencies used is desirable.

(b) The magnitude of the ratio $\frac{L}{R}$ should not be unreasonably small compared with the value obtained at $1 \mathrm{kc}$. This ratio enters into the sharpness of resonance ${ }^{3}$ which a circuit containing the coil would have.

It should be noted that $L$ denotes here the apparent inductance, which is always larger at radio than at audio-frequencies. It increases very rapidly as it approaches the natural ${ }^{4}$ frequency of the coil, but this corresponds to a frequency range within which the coil is of little practical value. ${ }^{5}$

(c) The percentage increase of radio-frequency resistance to the direct-current resistance. This value should not be unreasonably large.

(d) The percentage decrease of the ratio $\frac{L}{R}$ at radio-frequencies with respect to the value at audio-frequencies $(1 \mathrm{kc})$. This value should not be unreasonably large.

(e) The apparent inductance. This should not be too large compared with the value at $1 \mathrm{kc}$, because the increase is mostly due to the coil capacity.

All five properties show certain merits of a coil, for which reason their variation with frequency are plotted in Figures 7 to 10. It is of importance that a coil have a radio-frequency resistance which is comparatively low as long as it does not require a shape and size of coil which is unusually bulky. The curve for properties $a$ and $b$ (figs. 8 and 10) are therefore of importance for rapid inspection of the results. The curves corresponding to $e$ (fig. 7) give a means for evaluating the capacity of a coil.

\section{DESCRIPTION OF TEST SAMPLES}

The comparisons were carried out only for coils of so-called "lowloss" type and did not include shapes which are seldom used for radio work at broadcast frequencies. As an exception, an ordinary two-layer coil was measured in order to illustrate the unusual changes taking place in such a coil. The various shapes of test coils are shown in Figure 2.

The inductance of all coils was adjusted to 291 microhenries at $1 \mathrm{kc}$, which is of the order of magnitude common in receiving equip-

${ }^{3}$ Circular No. 74 of the Bureau of Standards, Radio Instruments and Measurements, p. 36.

- The apparent increase of $L$ of a coil is mostly due to the capacity of the coil, which effect is, in general, much larger than the decrease of inductance due to a nonuniform current distribution in the conductor.

$s$ There are several natural frequencies of a coil which do not bear definite harmonic ratios to each other. 
ment for tuning to broadcast frequencies. For the sake of brevity the different shapes of coils are designated by capital letters, as is shown in Table 1. The kind of wire used is indicated by subscripts. Thus, $D_{28}$ indicates a honeycomb coil using No. 28 (AWG) d. c. c.

TABLE 1.-Key for the test coils, using no binder

\begin{tabular}{|c|c|c|c|}
\hline Kind of coil & Symbol & Kind of coil & Symbol \\
\hline 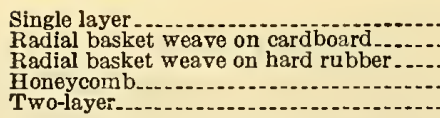 & $\begin{array}{l}\mathrm{A} \\
\mathrm{B} \\
\mathrm{C} \\
\mathrm{D} \\
\mathrm{E}\end{array}$ & $\begin{array}{l}\text { Narrow basket weave } \\
\text { Loose basket weave } \\
\text { Bank wound, two-layer } \\
\text { Bank wound, three-layer } \\
\text { Bank wound, four-layer }\end{array}$ & $\begin{array}{l}\mathbf{F} \\
\mathbf{T} \\
\mathbf{N} \\
\mathrm{H}\end{array}$ \\
\hline
\end{tabular}

wire, $T_{16}$ indicates a loose basket weave using No. $16(\mathrm{AWG})$ d.c. c. wire, and $N_{\mathrm{L}}$ a two-layer bank-wound coil using litz. All litz used was 32-38 d. c c. wire and corresponds roughly to the cross section of No. $23 \mathrm{AWG}$ wire. In this wire 32 No. $38 \mathrm{AWG}$ enameled copper wires are braided together. In order to have comparative tests on various binders, six single-layer coils were wound of the same size as $A_{28}$ and coated with the materials indicated in Table 2, which gives the designations used.

TABLE 2.-Key for test coils, using binder

\begin{tabular}{|c|c|c|c|}
\hline Binder used & Symbol & Binder used & Symbol \\
\hline $\begin{array}{l}\text { Shellac. } \\
\text { Commercial insulating varnish } \mathrm{A} \\
\text { Paraffin }\end{array}$ & $\begin{array}{l}\mathrm{K}_{28} \\
\mathrm{~L}_{28} \\
\mathrm{M}_{28}\end{array}$ & $\begin{array}{l}\text { Spar varnish } \\
\text { Collodion } \\
\text { Commercial insulating varnish } \mathrm{B} .\end{array}$ & $\begin{array}{l}P_{28} \\
Q_{28} \\
R_{28}\end{array}$ \\
\hline
\end{tabular}

Detailed information on all coils is given in Table 3 . The resistance at $1 \mathrm{kc}$ is, for the coils used, practically equal to the direct-current resistance. For this reason the direct-current resistance is utilized for evaluating the ratio $\frac{L_{\mathrm{o}}}{R_{\mathrm{o}}}$ at $1 \mathrm{kc}$.

TARLE 3.-Details of construction of test coils

\begin{tabular}{|c|c|c|c|c|c|c|c|}
\hline \multicolumn{2}{|r|}{ Coil } & \multirow[b]{2}{*}{ Wire $A W G$} & \multirow[b]{2}{*}{ Core } & \multirow[b]{2}{*}{$\begin{array}{l}\text { Dimensions of } \\
\text { winding }\end{array}$} & \multirow{2}{*}{$\begin{array}{l}\text { Direct- } \\
\text { cur- } \\
\text { rent } \\
\text { resist- } \\
\text { ance } \\
R_{\text {o in }} \\
\text { ohms }\end{array}$} & \multirow{2}{*}{$\begin{array}{l}\frac{L_{\mathrm{o}}}{\bar{R}_{\mathrm{o}}} \text { at I } \\
\text { ke in } \\
10^{-6} \\
\text { henries } \\
\text { in ohms }\end{array}$} & \multirow[b]{2}{*}{ Remarks } \\
\hline $\begin{array}{c}8 y \mathrm{~m} \\
\text { bol }\end{array}$ & Туре & & & & & & \\
\hline $\mathrm{A}_{28-.-}$ & Single layer. & $\begin{array}{l}\text { No. } 28 \text { d. c. c. } \\
\text { No. } 24 \text { d.c. c. }\end{array}$ & $\begin{array}{l}\text { Hard rubber.... } \\
\text { do }\end{array}$ & $\begin{array}{l}81 \mathrm{~mm} \text { diameter, } \\
31.5 \mathrm{~mm} \text { long, } \\
\text { about } 55 \text { turns. } \\
82 \mathrm{~mm} \text { diameter, }\end{array}$ & 3.15 & 9.24 & \\
\hline $\mathrm{A}_{10}$ & ...do_. & No.16 d.c.c. & -....do.. & $\begin{array}{l}\text { about } 60 \text { turns. } \\
163 \mathrm{~mm} \text { diam- } \\
\text { eter, } 67 \mathrm{~mm} \\
\text { long, about } 40 \\
\text { turns. }\end{array}$ & .28 & 103.8 & $\begin{array}{l}\text { W it h a bout } \\
\text { twice the diam- } \\
\text { eter as A } \\
\text { makes a coil of } \\
\text { about the same } \\
\text { proportions. }\end{array}$ \\
\hline
\end{tabular}


TABLE 3.-Details of construction of test coils-Continued

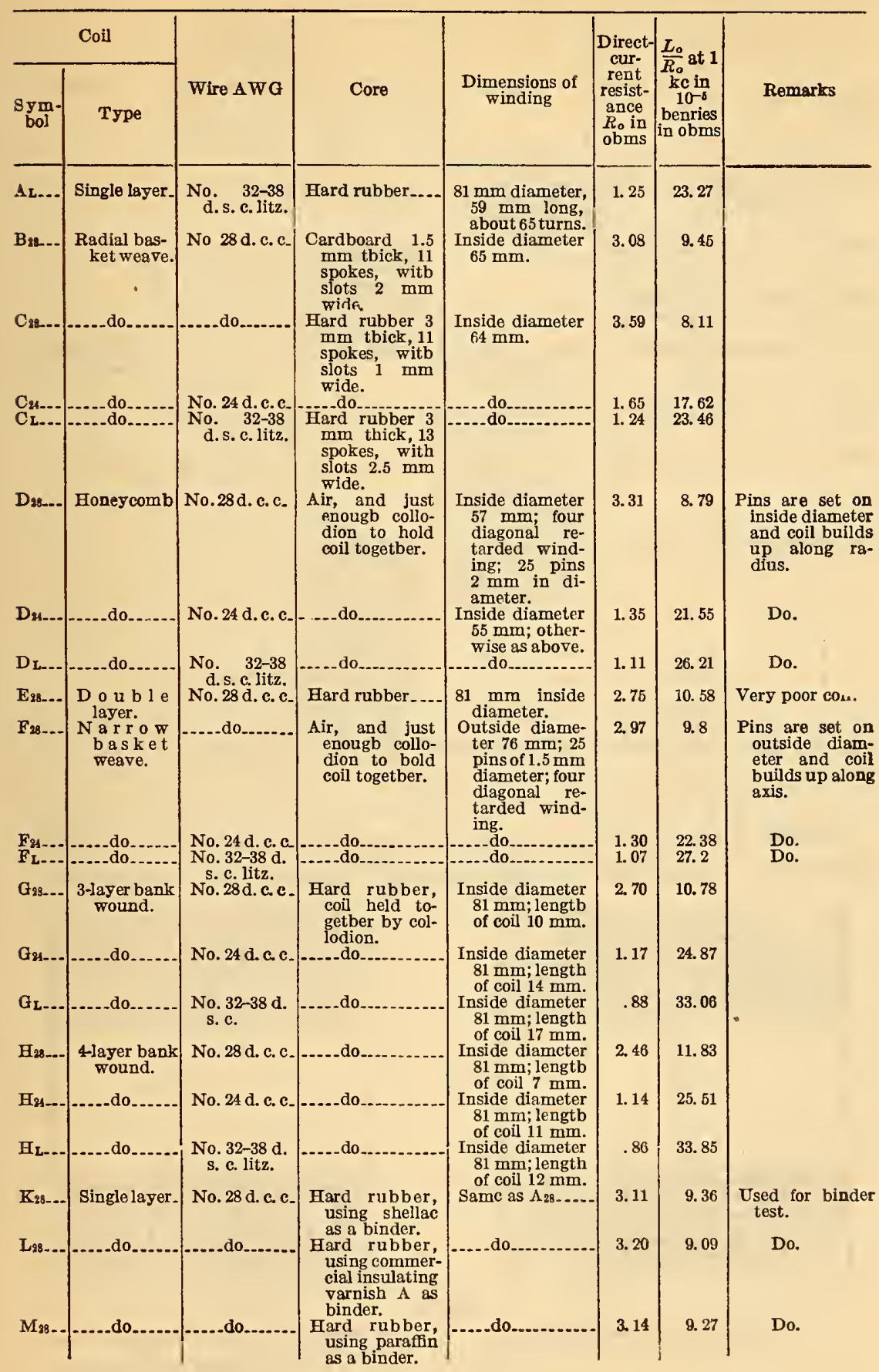




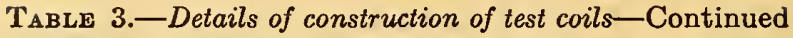

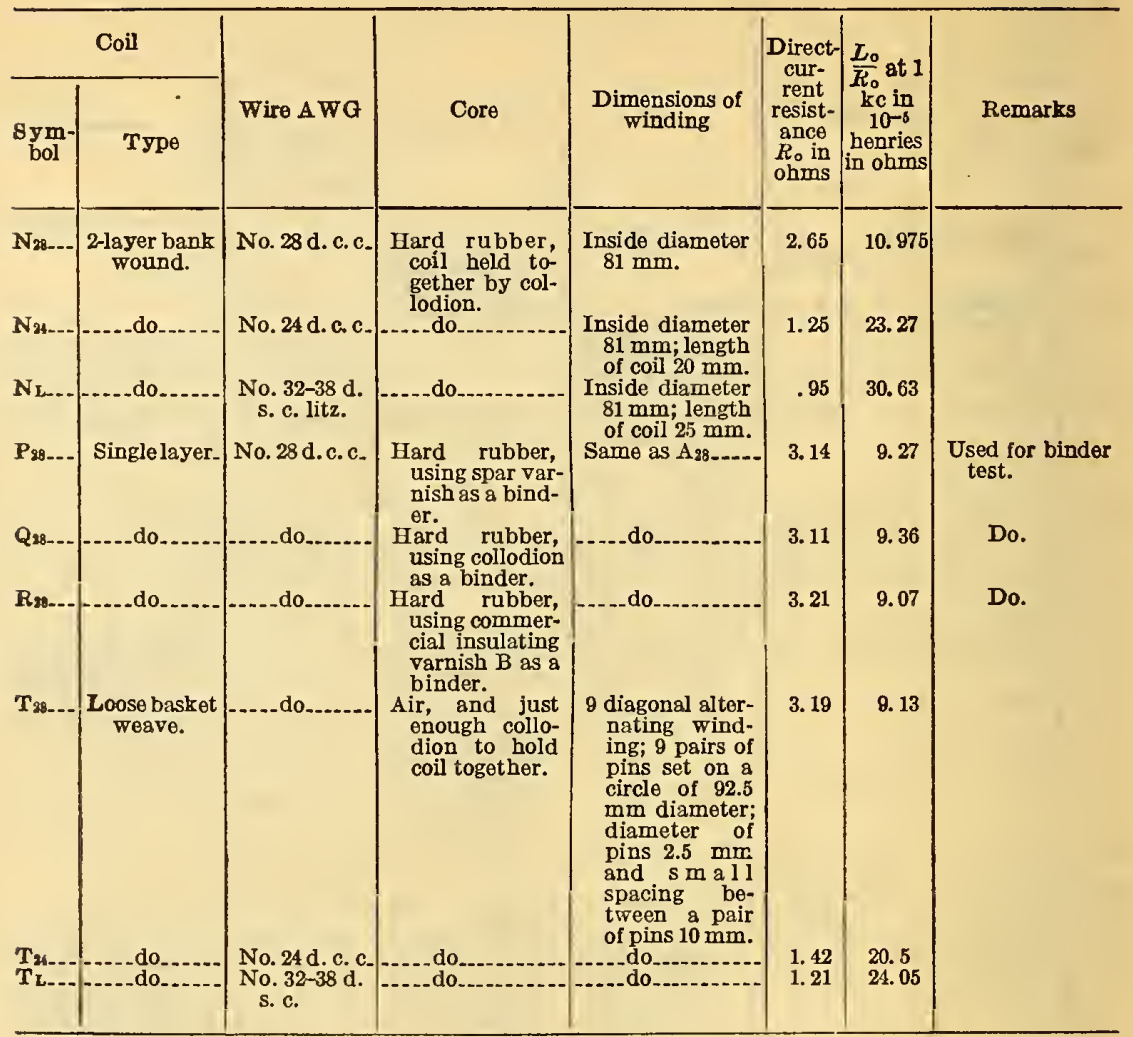

Figures 3 to 6 show how coils of these types are wound. Figure 3 illustrates the method used for winding a "three-layer bank wound"

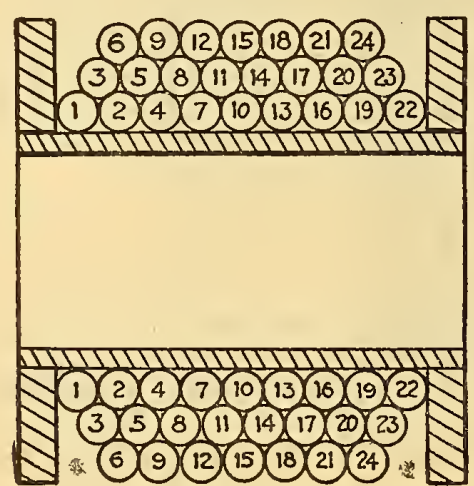

Three-layer bank winding

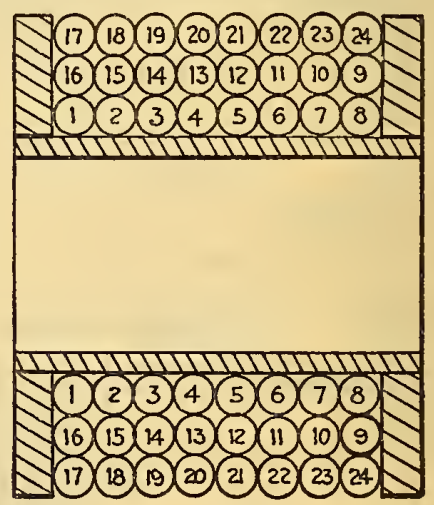

FIG. 3

Ordinary three-layer winding (useless for currents of the broadcasting range of frequency) 
coil in comparison with an ordinary three-layer coil. Figure 4 illustrates the method used in making the "narrow basket weave" coil, in which the coil is built up along the pins, which are removed after

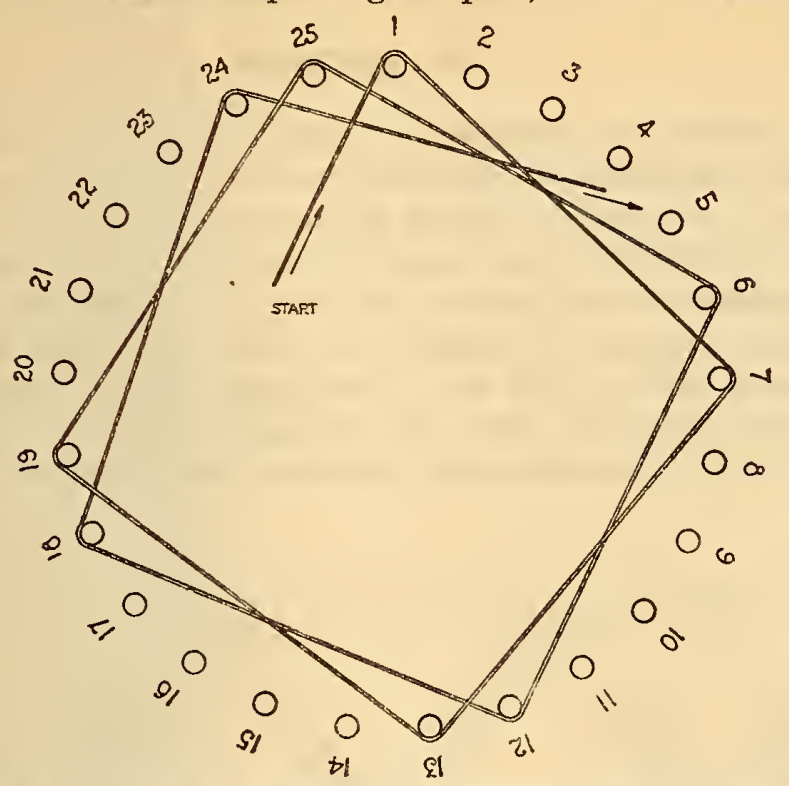

Fra. 4.-Narrow basket weave. Four diagonal retarded winding (using 25 pins set on a circle. Coil builds up along axis)

the coil is finished. Figure 5 illustrates the method used in winding the " loose basket weave" coil, which requires a pair of pins for each corner. A spacing of $10 \mathrm{~mm}$ between the two pins of a pair was

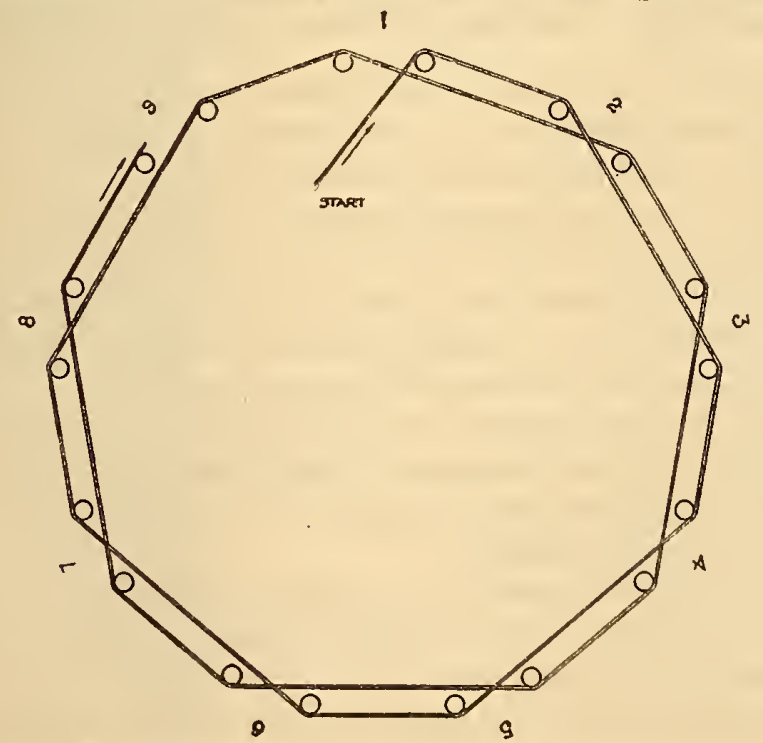

FIG. 5.-Loose basket weave. Nine diagonal alternating winding (using nine pairs of pins set on a circle. Coil builds up along the axis) $56961^{\circ}-25-2$ 
used. Figure 6 shows the method used in making the "honeycomb" coil. The zigzag winding is illustrated by the view of the entire cylinder surface. The winding is built up along the radii of the coil.

\section{RESULTS}

The results are exhibited in graphical form. Figure 7 gives curves for the apparent self-inductance of the various test coils as a function of frequency. As on all curve sheets, the dotted curves indicate the different coils using No. 32-38 litz. It is seen that the "loose basket weave" type of coil and the "single-layer" coils give the lowest apparent inductance over the entire range of broadcast frequencies $(500$ to $1,500 \mathrm{kc})$. This indicates that the coil capacity is comparatively low, while the ordinary two-layer coil $\left(\mathrm{E}_{28}\right)$ acts more or less like a condenser, since the coil capacity is exceedingly large.

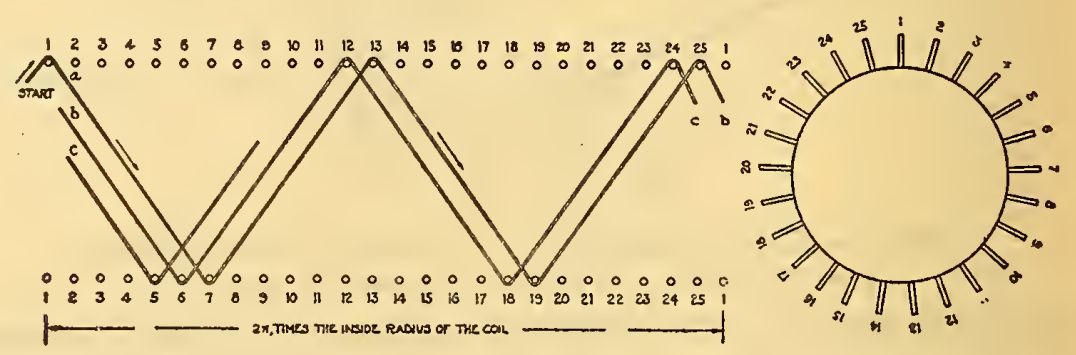

FIG. 6

Honeycomb coil. Four diagonal retarded winding (using 25 pins. Coil builds up along radius)

Cross-section of winding frame with the 25 pins

Figure 8 gives the curves for the radio-frequency resistance. It is seen again that the values of the resistance vary greatly. Naturally, the ordinary two-layer coil $\left(\mathrm{E}_{28}\right)$ has very large radio-frequency resistance within the broadcasting range. Though its direct-current resistance is only $2.75 \mathrm{ohms}$, the effective resistance at $500 \mathrm{kc}$ is 162 ohms, at $580 \mathrm{kc}$ it is $465 \mathrm{ohms}$, and at $748 \mathrm{kc}$ it is $1,800 \mathrm{ohms}$. The resistance increases very rapidly until it is mostly due to the dielectric resistance across the insulation between the layers. A three-layer coil wound in the ordinary way (ordinary multi-layer coil) and adjusted, like all coils discussed in this paper, to 291 microhenries at $1 \mathrm{kc}$ has a radio-frequency resistance of several thousand ohms at a frequency as low as $400 \mathrm{kc}$.

Figure 9 gives the curves for the ratio of the increase of the radiofrequency resistance over its direct-current value to the directcurrent value. It is seen that the loose basket weave and the singlelayer coils have low values; next comes the radial basket weave coil, 


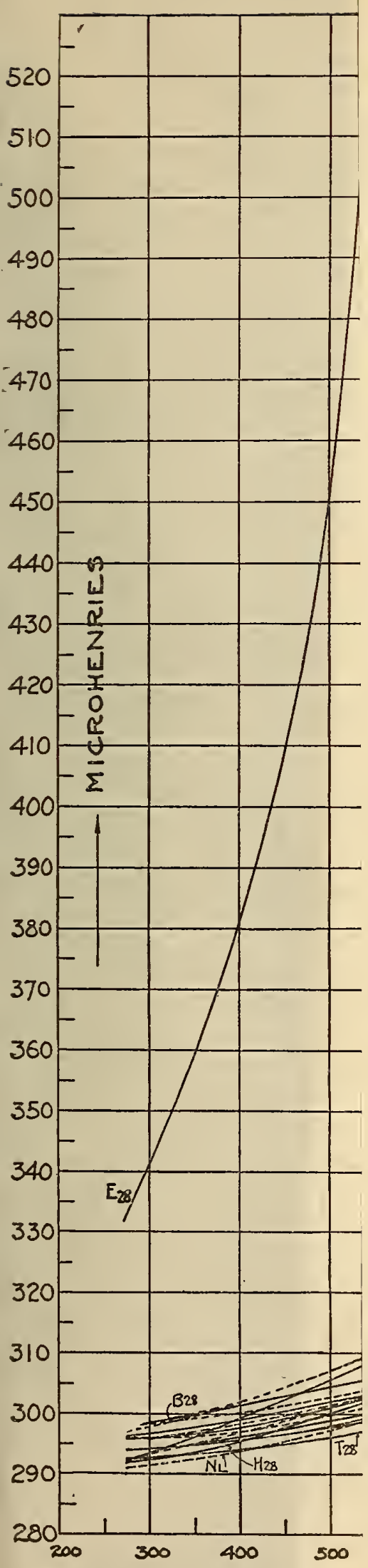

FIG. 7.-Apparent ineluclar 



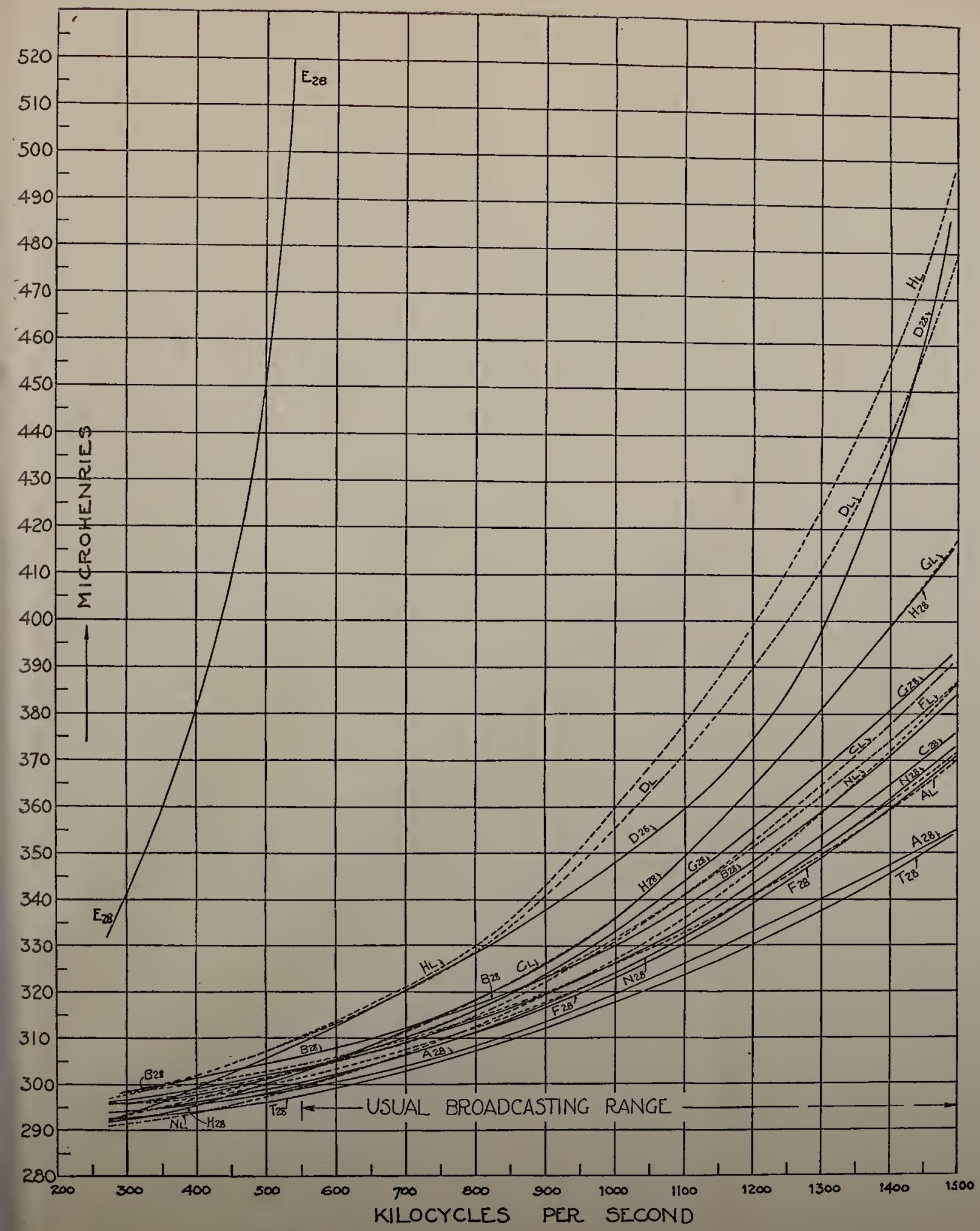

FIG. 7.-Apparent induclance at different frequencies (minimum inductance is 291 microhenries for all coils) 


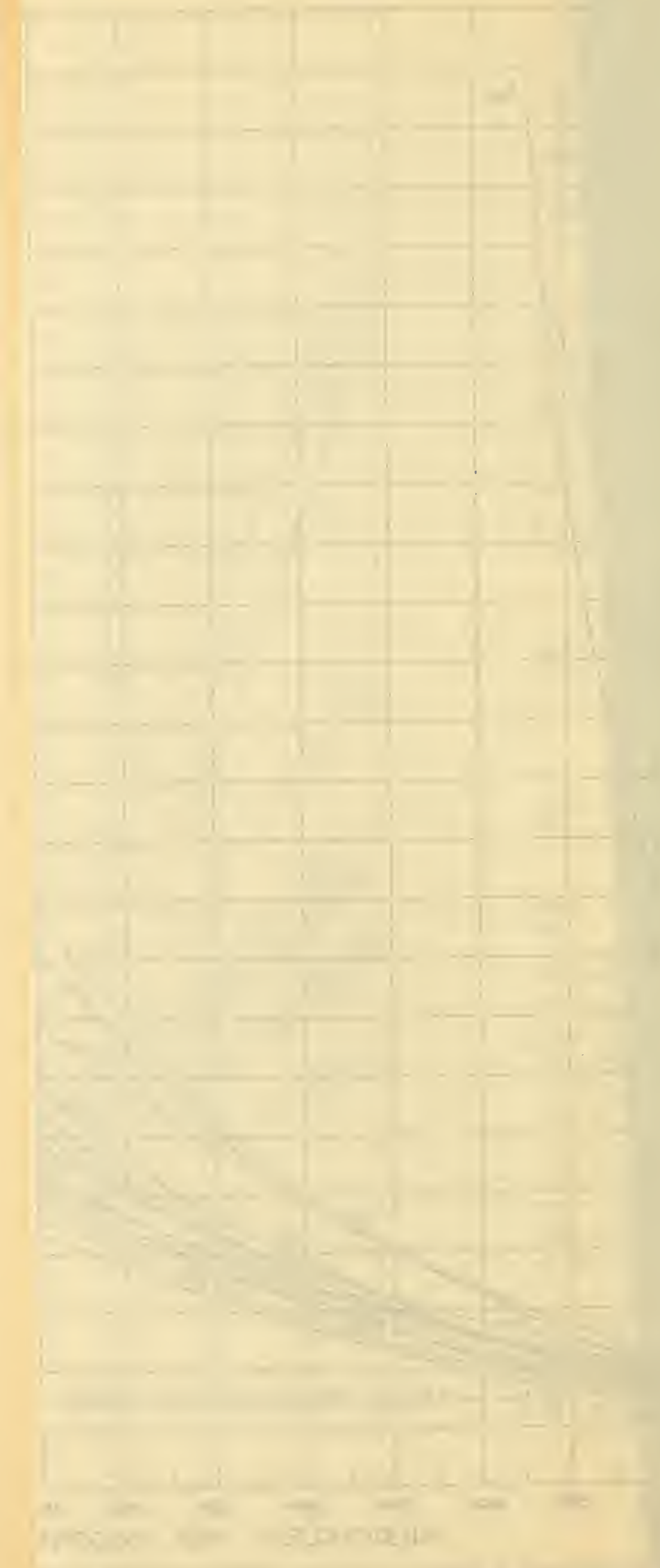




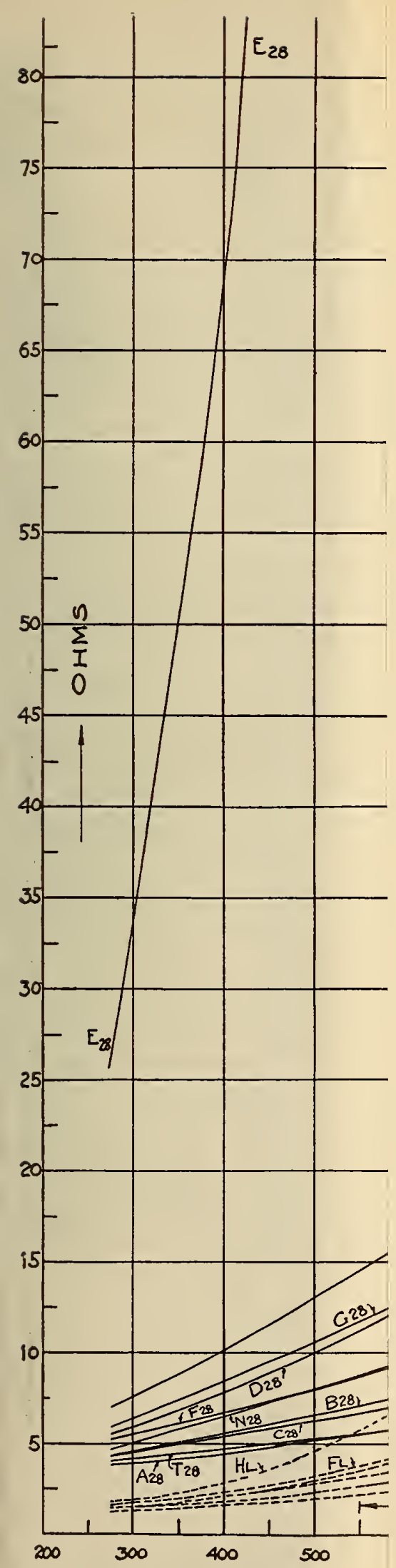





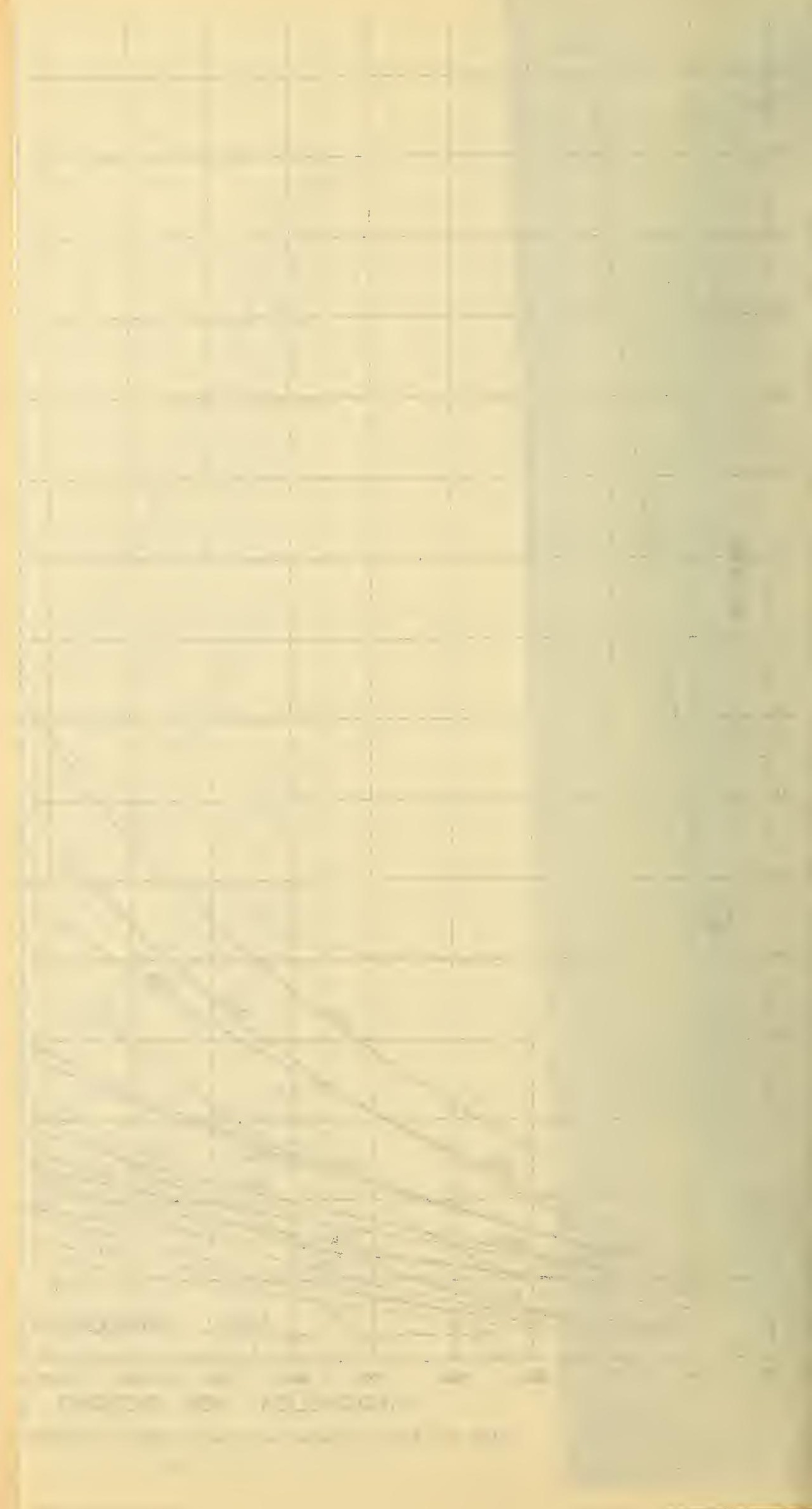





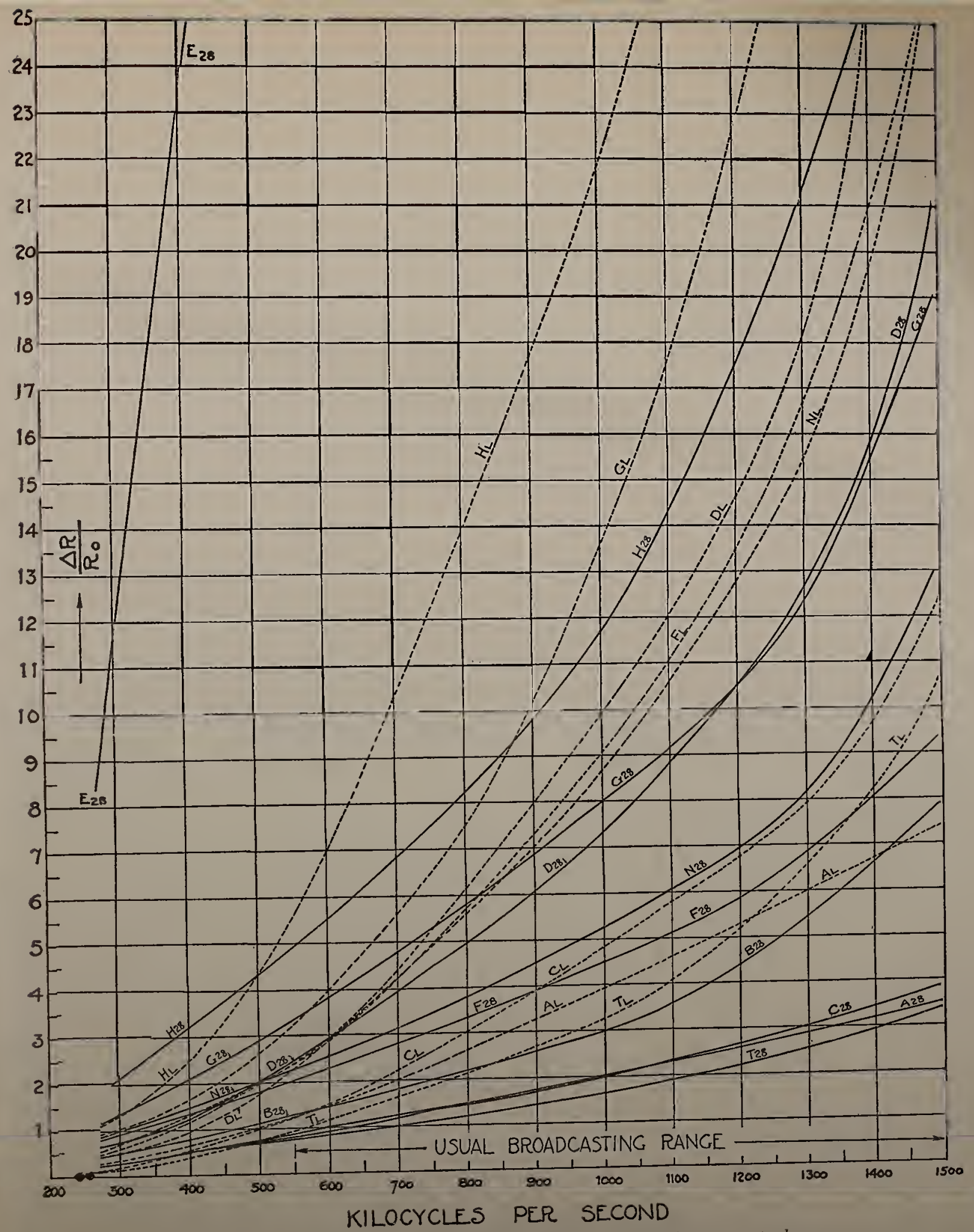

FiG. 9.-Ratio of the increase of resistance over its direct-current value to the direct-current value
56961-25. (Face p. 658.) N0.3 



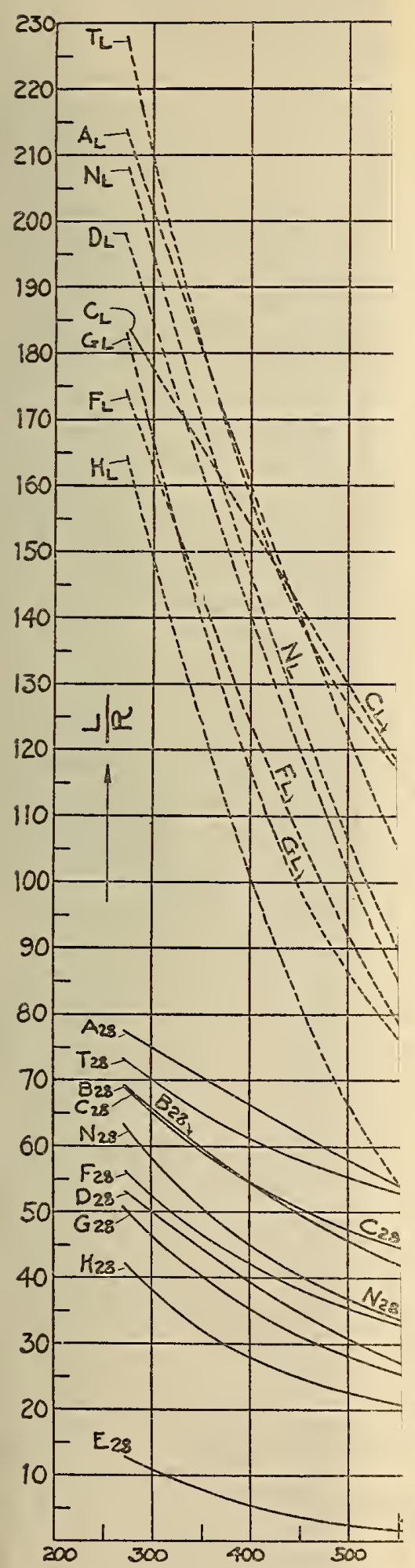





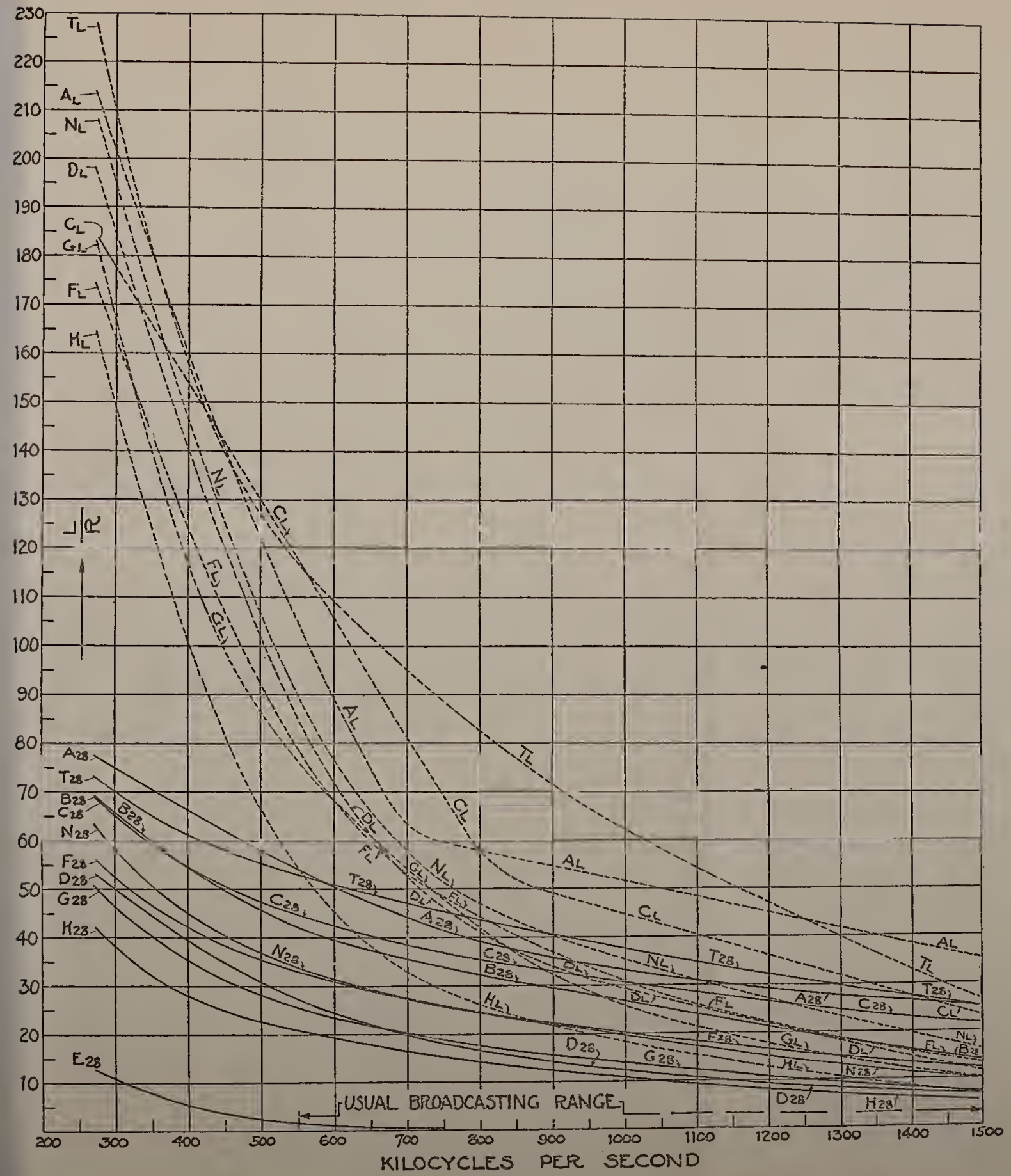

FIG. 10.-Ratio of inductance to resistance 



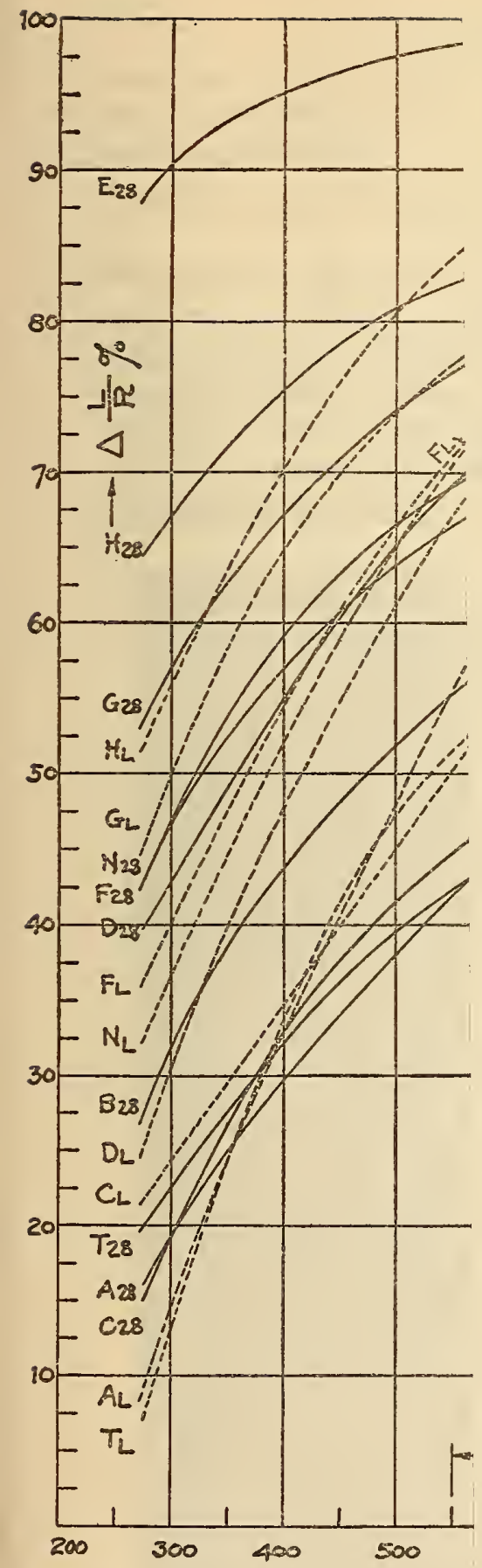

FIg. 11.-Percenta 



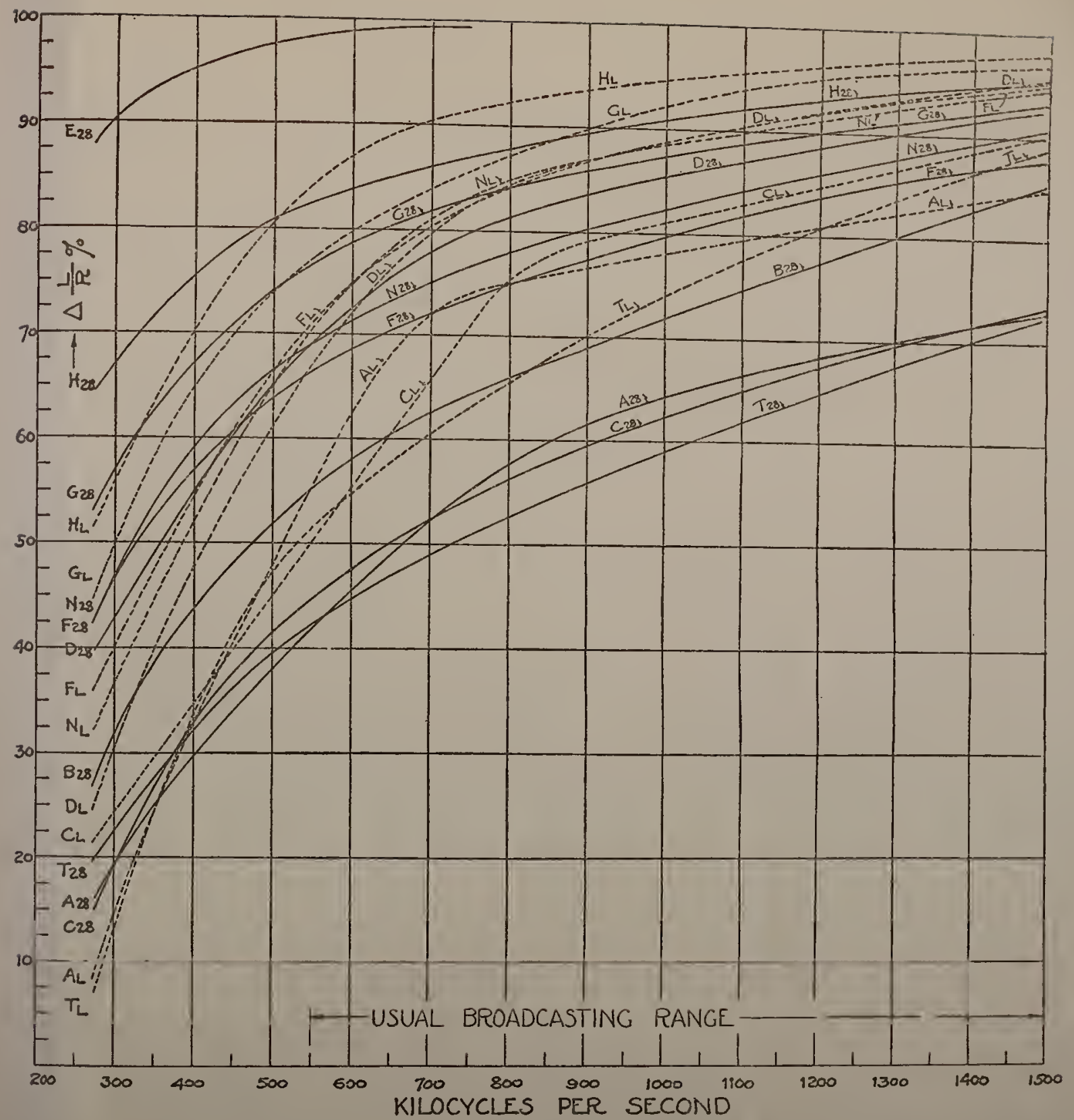

Fic. 11.-Percentage decrease in the ratio of inductance to resistance betono the value at $1 \mathrm{ke}$

Exhin-25. (Fich p. 6.5S) No.5 

using hard rubber for the core, while the four-layer bank wound, three-layer bank wound, and the honey^omb coils show considerable percentage increases.

Figure 10 gives the curves for the ratio $\frac{L}{R}$. It is always smaller than the ratio $\frac{L_{\mathrm{o}}}{R_{\mathrm{o}}}$ at $1 \mathrm{kc}$. Since the apparent inductance and the radio-frequency resistance increase with the frequency, this ratio in certain cases has only small changes although both $L$ and $R$ are changing rapidly. Nevertheless, these curves show about the same comparisons as the resistance curves.

$\underline{L}$

Figure 11 gives the curves for the percentage decrease in the ratio $\frac{L}{R}$ at different frequencies.

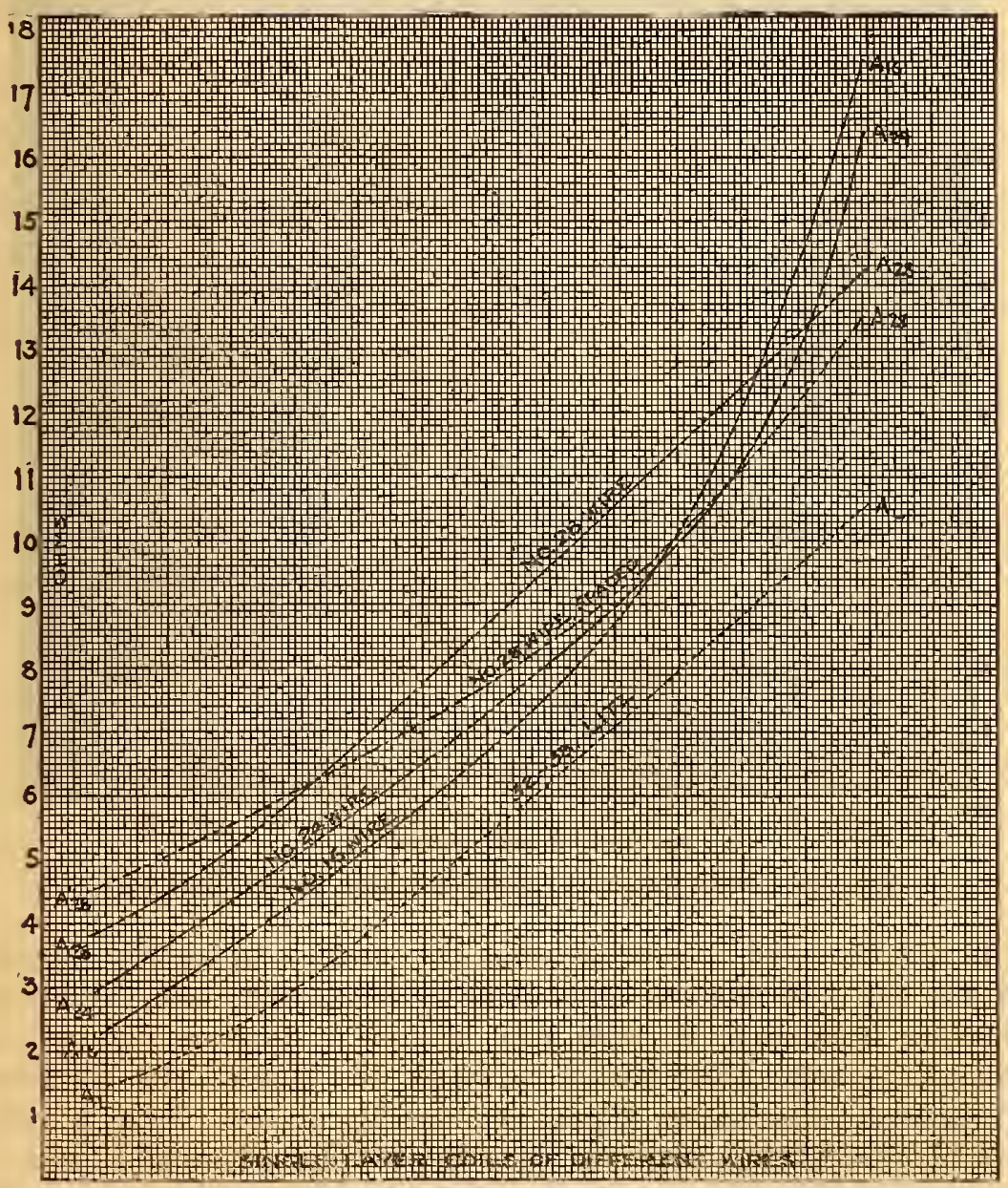
$2 \infty .+\infty$
$600 \quad 700 \cdot 800 \quad 900 \quad \$ 000 \quad i 100 \quad 1200$
KILOCYCLES PER SECOND

PIa. 12.-Radio-frequency resistance of single-layer coils 


\section{EFFECT OF THE KIND OF WIRE ON THE RESISTANCE OF A COIL}

In order to show the effect of the size of the wire, curves for the resistance for No. 28, No. 24, and No. 16 d. c. c. are plotted and compared among themselves and against No. 32-38 litz. These comparisons are shown in Figures 12 to 19.

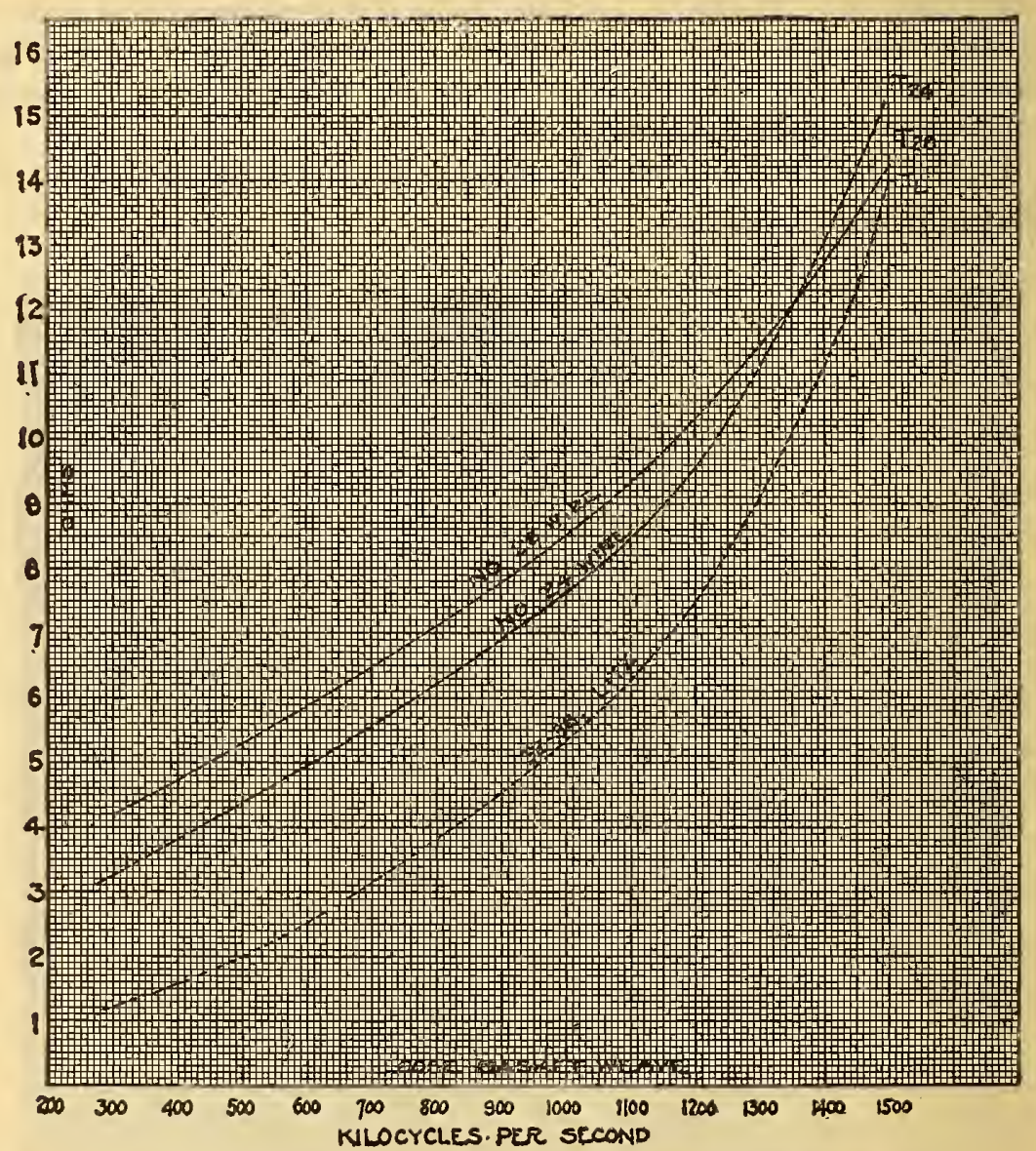

FIG. 13.-Radio-frequency resistance of loose basket-weave coils

It will be noted that in all cases litz, which corresponds roughly to No. 23 solid wire as regards its cross section, had the lowest effective resistance. If solid wire is used, it appears unnecessary to use wire larger than No. 24, although No. 16 gives, for the lower frequencies, resistances which are slightly lower. Such a large size of wire would, however, make the winding of certain types of coils more difficult and the size of the finished coil too large for 
convenient use in receiving sets. Figure 12 shows a single-layer coil the turns of which are spaced by a distance equal to the diameter of the wire. There seems to be no material reduction in resistance except at the higher frequencies.

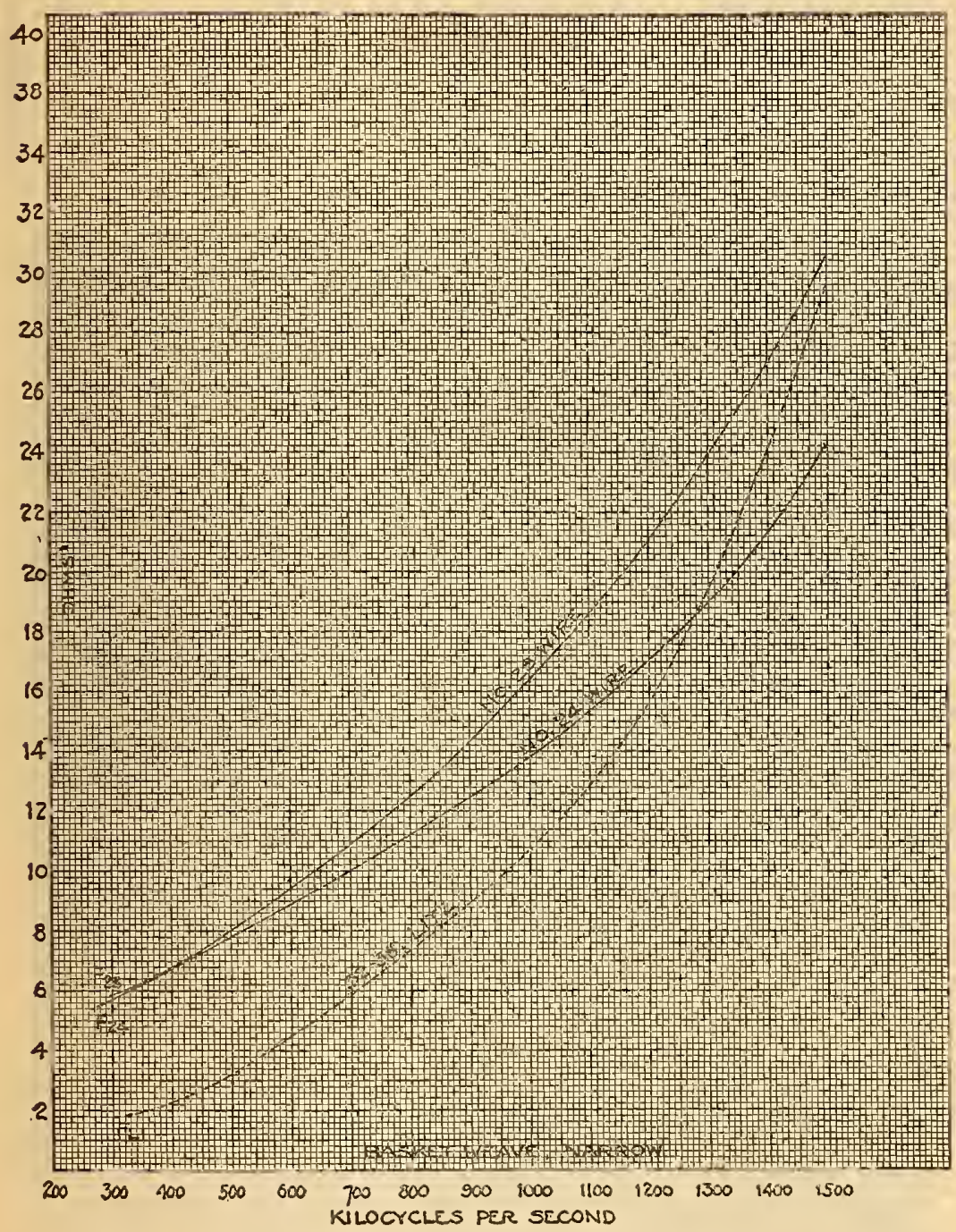

FIG. 14.-Radio-frequency resistance of narrow basket-u'eave coils

\section{EFFECT OF BROIEN STRANDS IN LITZ WIRE}

The question is often asked concerning litz wire as to the effect on the resistance of some of the strands being broken or not connected at the respective ends. 
TABLE 4.-Resistance of litz wire Nos. 32-38, at $750 \mathrm{kc}$

\begin{tabular}{|c|c|c|c|c|c|c|c|}
\hline Broken strands & $\begin{array}{l}\text { Resist- } \\
\text { ance }\end{array}$ & Broken strands & $\begin{array}{c}\text { Resist- } \\
\text { ance }\end{array}$ & Broken strands & $\begin{array}{l}\text { Resist- } \\
\text { ance }\end{array}$ & Broken strands & $\begin{array}{l}\text { Resist- } \\
\text { ance }\end{array}$ \\
\hline $\begin{array}{l}0 \\
0 \\
1 \\
3 \\
3 \\
4 \\
6\end{array}$ & $\begin{array}{r}\text { Ohms } \\
3.1 \\
3.2 \\
3.2 \\
3.3 \\
3.3 \\
3.3 \\
3.4 \\
3.5\end{array}$ & $\begin{array}{r}8 \\
9 \\
10 \\
11 \\
13 \\
14 \\
15\end{array}$ & $\begin{array}{r}\text { Ohms } \\
3.6 \\
3.8 \\
3.8 \\
4.2 \\
4.4 \\
4.4 \\
4.4 \\
4.7\end{array}$ & $\begin{array}{l}16 \\
17 \\
18 \\
19 \\
20 \\
21 \\
22\end{array}$ & \begin{tabular}{|r} 
Ohms \\
5.4 \\
5.6 \\
6.1 \\
6.4 \\
7.4 \\
7.6 \\
7.8 \\
8.4
\end{tabular} & $\begin{array}{l}24 \\
25 \\
26 \\
27 \\
28 \\
29 \\
30 \\
31\end{array}$ & $\begin{array}{r}\text { Ohms } \\
9.5 \\
10.8 \\
13.5 \\
14.4 \\
16.5 \\
21.7 \\
42.4 \\
51.6\end{array}$ \\
\hline
\end{tabular}

Lltz used is Nos. $32-38$ and has 32 strands of No. 38 AWG enameled wire braided together.

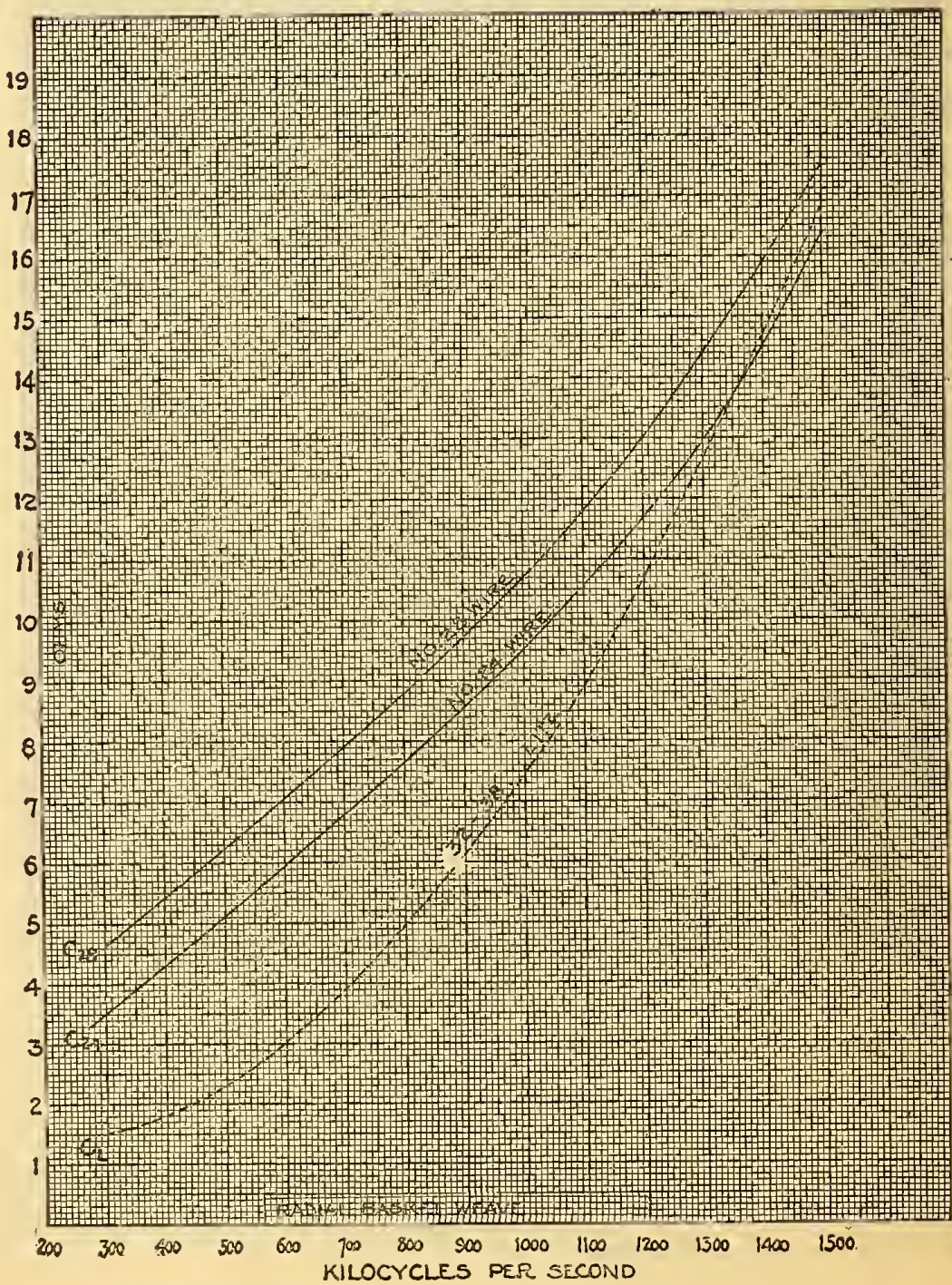

Fıg. 15.-Radio-frequency resistance of radial basket-weave coils 
Table 4 shows that it is not so serious to have a few strands broken, since the radio-frequency current apparently finds its way back

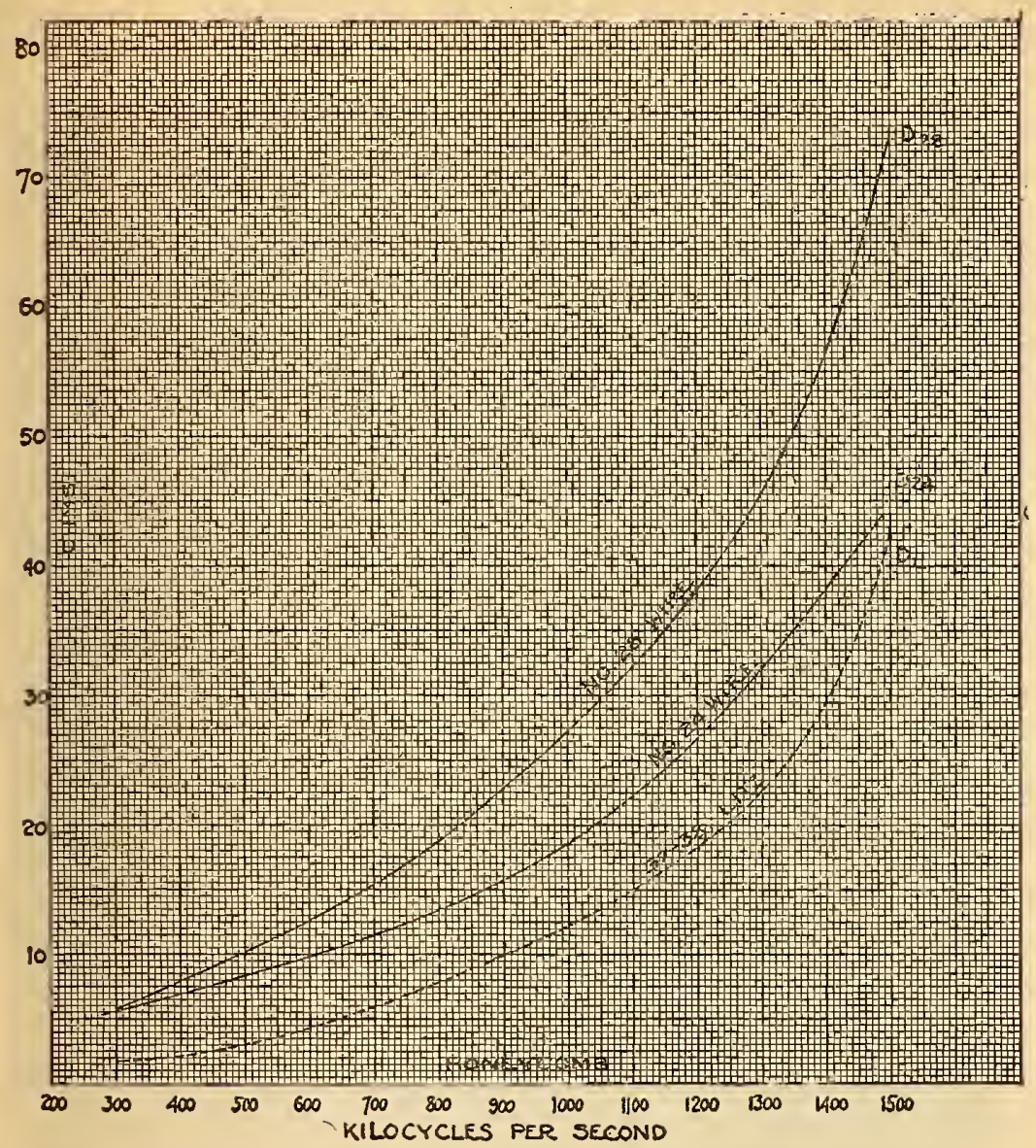

FIG. 16.-Radio-frequency resistance of honeycomb coils

across the strands. Even if, say, six strands are broken, the radio-. frequency resistance is $3.4 \mathrm{ohms}$ as compared with $3.1 \mathrm{ohms}$ for perfect strands. 


\section{EFFECT OF BINDER ON THE EFFICIENCY OF COILS}

The binders used in this test were each applied to a single-layer coil, and just enough of it to cover the entire surface. The varying nature of the different binders probably resulted in different thick-

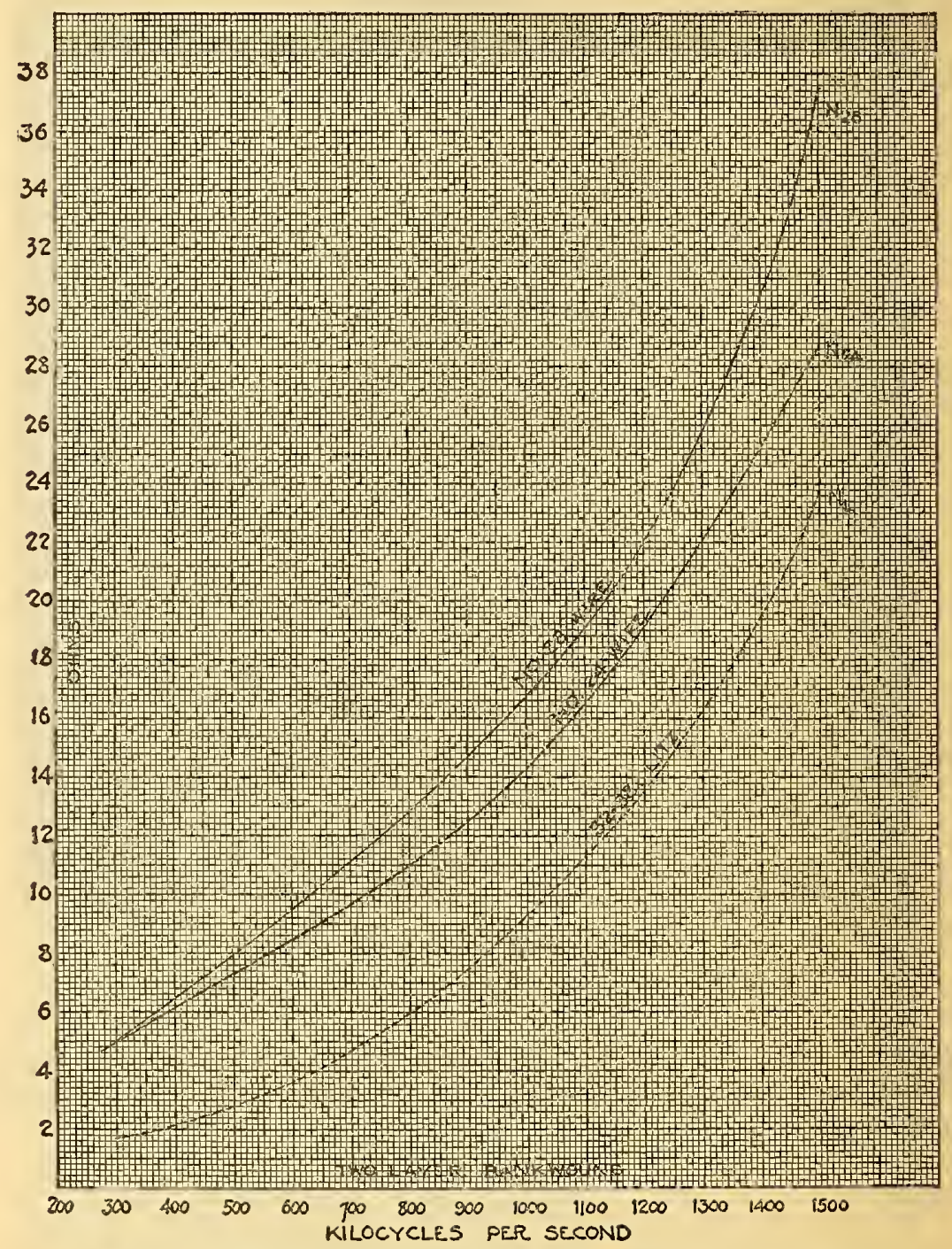

FIG. 17.-Radio-frequency resistance of two-layer bank-wound coils

nesses. The coils in every case were dried thoroughly. The measurements were a little difficult when a binder was used, even though great care was taken to have the binder dried. For instance, in 
some cases the effective resistance of a coil using a binder came out smaller by a fraction of an ohm than for the coil using no binder. The binder seemed to make an accurate resistance adjustment more difficult.

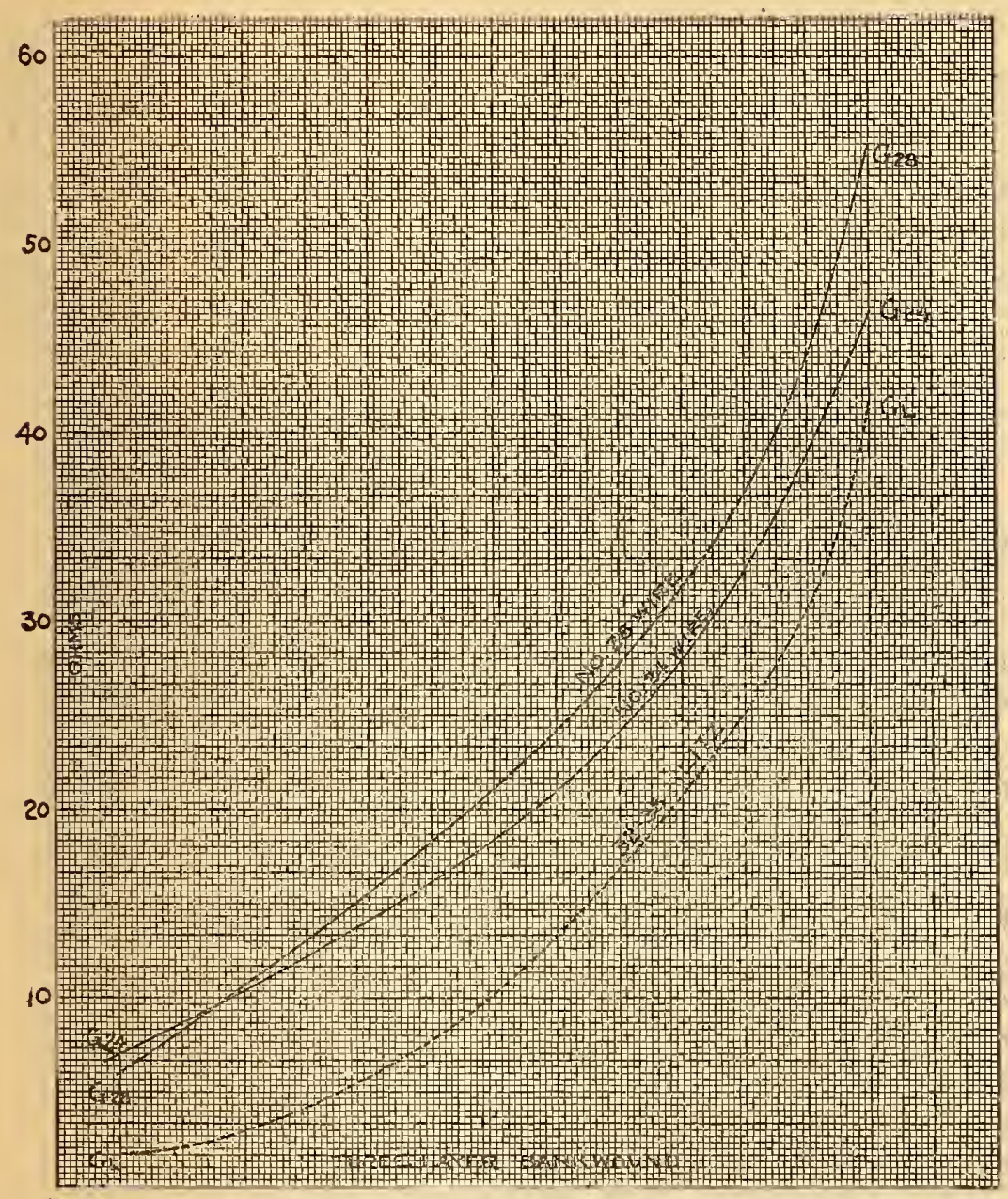

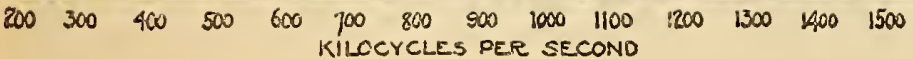

Fia. 18.-Radio-frequency resistance of three-layer bank-wound coils 
TABLE 5.-Variation with frequency of radio-frequency resistance (in ohms) for different binders

\begin{tabular}{|c|c|c|c|c|c|c|}
\hline Frequency in kilocycles & no binder & $\begin{array}{c}\text { Q28, } \\
\text { collodion }\end{array}$ & $\begin{array}{l}\mathrm{R}_{28}, \text { com- } \\
\text { mercial } \\
\text { insulating } \\
\text { varnish } \mathrm{B}\end{array}$ & $\mid \begin{array}{l}\mathrm{L}_{28}, \text { com- } \\
\text { mercial } \\
\text { insulating } \\
\text { varnish A }\end{array}$ & $\underset{\text { shellac }}{\mathrm{K}_{28}}$ & $\begin{array}{c}M_{28} \\
\text { paraffin }\end{array}$ \\
\hline $\begin{array}{l}300 \\
600 \\
600\end{array}$ & \begin{tabular}{l|}
3.9 \\
4.4 \\
5.1 \\
5.9 \\
6.7
\end{tabular} & $\begin{array}{l}3.8 \\
4.3 \\
4.9 \\
5.5 \\
6.3\end{array}$ & $\begin{array}{l}3.9 \\
4.4 \\
5.0 \\
5.7 \\
6.6\end{array}$ & $\begin{array}{l}3.8 \\
4.3 \\
4.8 \\
5.3 \\
6.0\end{array}$ & $\begin{array}{l}3.7 \\
4.1 \\
4.8 \\
5.6 \\
6.6\end{array}$ & $\begin{array}{l}3.9 \\
4.6 \\
5.2 \\
6.0 \\
6.8\end{array}$ \\
\hline $1,000 \ldots$ & \begin{tabular}{r|}
7.6 \\
8.5 \\
9.4 \\
10.3
\end{tabular} & $\begin{array}{r}7.1 \\
8.0 \\
8.9 \\
10.0\end{array}$ & $\begin{array}{r}7.5 \\
8.5 \\
9.6 \\
10.8\end{array}$ & $\begin{array}{r}6.8 \\
7.7 \\
8.8 \\
10.1\end{array}$ & $\begin{array}{r}7.6 \\
8.8 \\
10.1 \\
11.4\end{array}$ & $\begin{array}{r}7.8 \\
9.0 \\
10.3 \\
11.8\end{array}$ \\
\hline 1,300 & $\begin{array}{l}11.3 \\
12.2 \\
13.2 \\
14.2\end{array}$ & $\begin{array}{l}11.0 \\
12.1 \\
13.2 \\
14.4\end{array}$ & $\begin{array}{l}12.0 \\
13.3 \\
14.6 \\
15.9\end{array}$ & $\begin{array}{l}11.5 \\
13.1 \\
14.7 \\
16.4\end{array}$ & $\begin{array}{l}12.8 \\
14.2 \\
15.7 \\
17.2\end{array}$ & $\begin{array}{l}13.3 \\
15.0 \\
16.7 \\
18.5\end{array}$ \\
\hline
\end{tabular}

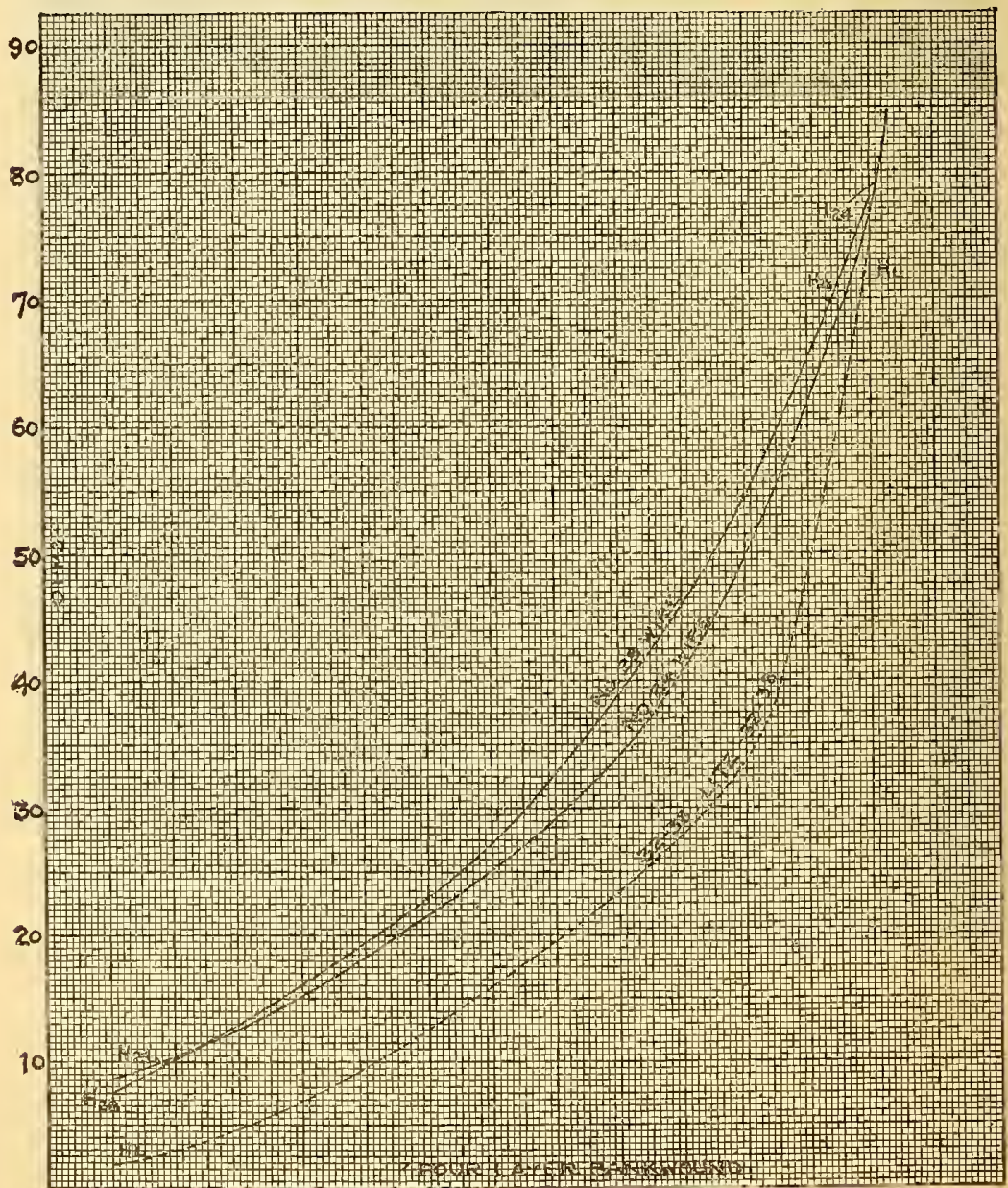

$\begin{array}{lllllllllllllllll}200 & 300 & 400 & 500 & 600 & 700 & 800 & 900 & 1000 & 1100 & 1200 & 1300 & 1.400 & 1500\end{array}$ KILOCYCLES OER SEEOND

PIG. 19.-Radio-frequency resistance of four-layer bank-wound coils 


\section{SUMMARY}

1. The various experimentally obtained curves given in this paper can be used as design bases for comparing coils of six types for any frequency in the broadcast range. For these data to apply it is necessary that the coils be constructed in accordance with the information given in Table 3. The coil dimensions are such that the coils are applicable to modern broadcast reception. A statement of the important characteristics of coils is given in the introduction.

2. The curves shown in Figures 9 and 11 give the changes of resistance and of $\frac{L}{R}$ with frequency. High values of these ratios do not in all cases correspond to high values of radio-frequency resistance. In some cases, for instance, a particular coil has a relatively high value for $\frac{\Delta R}{R_{0}}$, although the actual radio-frequency resistance is not large, because the direct current resistance is comparatively low.

3 . The curves of Figures 8 and 10 give the actual radio-frequency resistance and ratio of inductance to resistance at various frequencies.

4. Of the coils measured the loose basket weave coil and the single-layer coil, and next to them the radial basket weave coil wound on hard rubber, have the lowest radio-frequency resistance. The four-layer bank-wound coil and the honeycomb winding have the highest resistance. This can not, however, be generalized to other frequency ranges. For instance, for low-frequency sets $(20$ to $100 \mathrm{kc}$ ) the multilayer bank-wound coil and the honeycomb coil have relatively low resistance, and besides are good coils mechanically while the loose basket weave coil has no special advantage and the single-layer coil can not be used on account of excessive size.

5. There appears to be little reduction of resistance at the lower frequencies in spacing the turns, so that the advantage of getting a smaller resistance is small compared with the disadvantage of requiring a coil twice as long.

6. The use of Nos. 32-38 litz gives coils of somewhat lower resistance than coils wound with solid wire of the same cross section. No. 24 AWG solid wire has less resistance than No. 28 wire, and No. 16 wire for a certain range has less resistance than Nos. 24 and 28 wire. If solid wire is used it does not appear necessary to use wire larger than No. 24 AWG. This conclusion can not, of course, be extended outside the broadcast frequency range; for instance, No. 16 solid wire would be better for frequencies above 5,000 kc. 
7. All the insulating materials which were used as binders caused very slight increases in the resistance of the coils. Collodion seems best, and also has the inherent advantage of drying rapidly after application to the coil. This is of especial advantage in the construction of a bank-wound coil.

Washington, May 25, 1925. 